\author{
EESTI NSV TEADUSTE AKADEEMIA TOIMETISED. XVI KÖIDE \\ KEEMIA * GEOLOOGIA. 1967, Nr. 3 \\ ИЗВЕСТИЯ АКАДЕМИИ НАУК ЭСТОНСКОЙ ССР. ТОМ ХVI \\ ХИМИЯ * ГЕОЛОГИЯ. 1967, № 3
}

\title{
H. КЛЕСМЕHT
}

\section{АНАЛИЗ КЕТОНОВ ХРОМАТОГРАФИЧЕСКИМИ МЕТОДАМИ}

В природных соединениях и продуктах синтеза присутствуют кислородные соединения, в которых кислород играет различную роль. Функция кнслорода обусловливает химические свойства соединения, превращает его в спнрт, кетон, эфир или другое. Углеводородный радикал кислородного соедннения оказывает на его химические свойства меньше влияния, от него зависят физические показатели.

Сланцевая смола также содержит много кислородных соединений, нз которых наиболее изучены фенолы. Последние поддаются исследованию легче других групп. Это объясняется следующими причинами: фенолы легко отделить от других соединений, используя их кислые свойства. Все они содержат ароматический радикал, который связывает шесть атомов углерода.

Значительно труднее анализ кислородных соединений, имеющих нейтральный характер. Отделение групп (кетоны, альдегиды, простые и сложные эфиры) путем химической реакции сложнее и часто не проходит количественно. Если рассматривать только карбонильные соединения, то выясняется, что количество изомеров их в несколько раз превышает количество фенолов с равным чнслом углеродных атомов. Это обусловлено тем, что карбонильное соединение может иметь как алифатическую цепь, так и нафтеновое кольцо. Возможно также присутствие ненасыщенных связей, что вызывает, как и у нафтеновых структур, появление цис-транс-изомеров.

В сланцевой смоле фенолы и нейтральные кислородные соединения присутствуют в приблизительно равных количествах. Низкомолекулярная часть фенолов сравнительно хорошо изучена, но о составе нейтральных кислородных соединений известно мало. Причина этого заключается в вышеотмеченных аналитических трудностях. До сих пор при анализе нейтральных кислородных соединений ограничивались определением функциональных групп. Установлено, что в них присутствует много карбонильных соединений; химическими методами идентифицировано несколько алифатических и циклических кетонов [1 ${ }^{1} \mathrm{j}$.

В последние годы методы анализа органических соединений дополнились хроматографическими методами, разработан комплексный хроматографический мегод для анализа фенолов $\left[{ }^{2}\right]$. Цель настоящего исследования состояла в разработке аналогичного метода для анализа кетонов. Метод был проверен при анализе одной фракции, выделенной из продуктов полукоксования сланца и состоящей в основном из кетонов.

\section{Характеристика исследованной фракции}

Низкомолекулярные кислородные соединения - кетоны и спирты хорошо растворяются в воде, но при содержании $4-8$ атомов углерода их растворимость значительно понижается. Подсмольная вода, полу- 
чаемая при полукоксовании сланца, растворяет карбонильные соединения смолы, в основном ацетон и метилэтилкетон. Содержание высших кетонов в концентрате, выделенном из воды, не превышает 20\%. В настоящей работе исходным вещесгвом служила одна фракция последних. Общая характеристика концентрата кетонов представлена в работе [3]. Фракция была выделена путем ректификации в колонке эффективностью 50 теоретических тарелок. Ее показатели были следующие:

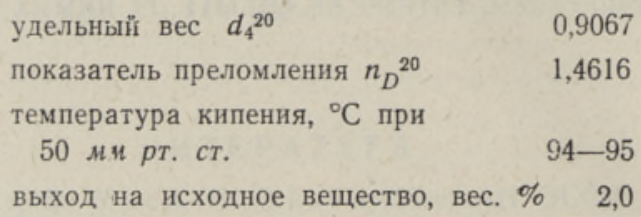

Фракция имела запах азотистых соединений, который у соседних фракций был меньше или отсутствовал. Судя по температуре кипения, в фракции могут присутствовать соединения, приведенные в табл. 1 . Среди них имеются также спирты; возможность их присутствия выяснилась в ходе работы. Количество исходного вещества было 5 г. Так как для анализа использовали микрометоды, этого количества оказалось достаточно.

Таблица 1

Показатели некоторых кислородных и азотистых соединений $\left[{ }^{4}\right]$

\begin{tabular}{|c|c|c|c|}
\hline Вещество & $\begin{array}{l}\text { Температура } \\
\text { кипения, }{ }^{\circ} \mathrm{C}\end{array}$ & $\begin{array}{l}\text { Удельный } \\
\text { вес } d_{4}^{20}\end{array}$ & $\begin{array}{l}\text { Показатель } \\
\text { преломле- } \\
\text { ния } n_{D}{ }^{20}\end{array}$ \\
\hline $\begin{array}{l}\text { Октанон-2 } \\
\text { Октанон-3 } \\
\text { 2-Метилциклогексанон } \\
\text { 3-Метилциклогексанон } \\
\text { 4-Метилциклогексанон } \\
\text { н-Гептанол-1 } \\
\text { н-Гептанол-2 } \\
\text { н-Гептанол-3 } \\
\text { Циклогексанол } \\
\text { 2-Метилциклогексанол } \\
\text { 2,4-Диметилпиридин } \\
\text { 3,4-Диметилпиридин } \\
\text { 3-Этилпиридин } \\
\text { 4-Этилпиридин } \\
\text { н-Октиламин-1 } \\
\text { н-Октиламин-2 }\end{array}$ & $\begin{array}{l}173,5 \\
168 \\
156 \\
169 \\
168-9 \\
176 \\
160,4 \\
163-6 \\
161,5 \\
165 \\
157,1 \\
163,5-4,5 \\
165,3 \\
166 \\
179,6 \\
164-6\end{array}$ & $\begin{array}{l}0,818 \\
0,850 \\
0,9248 \\
0,915 \\
0,9136 \\
0,8219 \\
0,8187 \\
0,8282 \\
0,9449 \\
0,937 \\
0,9493 \\
0,945 \\
0,936 \\
0,777 \\
0,7721\end{array}$ & $\begin{array}{l}1,4161 \\
1,4505 \\
1,4456 \\
1,4432 \\
1,4241 \\
1,4213 \\
1,4279 \\
1,4656 \\
1,4640\end{array}$ \\
\hline
\end{tabular}

\section{Схема анализа}

Использовалась комбинация нескольких хроматографических методов: газо-жидкостной, тонкослойной и реакционной. Поскольку концентрат карбонильных соединений содержит соединения из других групп, оказалось необходимым определить их химическими реакциями и идентифицировать с помощью дифференциальных хроматограмм. Общий ход анализа представлен на схеме. Каждую операцию проводили предварительно с эталонами, потом с фракцией. Много внимания в этой работе уделялось тонкослойной хроматографии. 


\section{Газохроматографический анализ кетонов}

Кетоны являются относительно высокополярными соединениями, для хроматографии которых требуются инертные носители. В качестве неподвижной фазы использовали карбовакс, носителя - стеклянные шарики [5] и хромосорб, обработанный гексаметилдисилазаном [6]. Анализы гроводили на газовых хроматографах УХ-I и «Пай» (с радиоактивным детектором). Характеристика использованных колонок приведена в табл. 2. Основную работу проводили на аппарате «Пай», второй хрома-

Таблица 2

Характеристика газохроматографических колонок и условий разделения

\begin{tabular}{|c|c|c|c|c|c|}
\hline \multirow{2}{*}{$\begin{array}{l}\text { № ко- } \\
\text { лонки }\end{array}$} & \multicolumn{2}{|c|}{ Неподвижная фаза } & \multirow{2}{*}{ 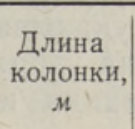 } & \multirow{2}{*}{$\begin{array}{l}\text { Tемпе- } \\
\text { ратура, } \\
{ }^{\circ} \mathrm{C}\end{array}$} & \multirow{2}{*}{ Носитель } \\
\hline & название & $\begin{array}{c}\% \text { от но- } \\
\text { сителя }\end{array}$ & & & \\
\hline
\end{tabular}

1 Полиэтиленгликоль 4000

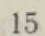

2 Апиезон $D$

3 Твин 80

Ацетонилацетон

Полиэтиленгликоль 4000

15

15

15

20

20

20
1,2

3

6

6

6
Целлит 545; 0,120,16 мм

Хромосорб $W ; 0,25-$ 0,35 мм

Диатомит Т3К; 0,20,3 м.M

100,180

20 То же

200 Силоцель 22

тограф служил для препаративного разделения и реакционной хроматографии. При аналитической работе целесообразно использовать не менее двух колонок с различными фазами. В этой работе таковыми были полиэтиленгликоль и апиезон (колонки № 1 и 2).

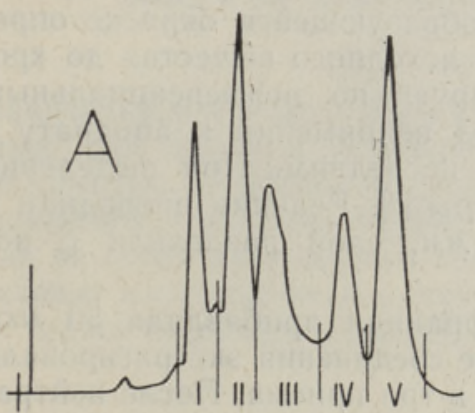

$\begin{array}{lllll}0 & 10 & 20 & 30 & 40 \text { мUн }\end{array}$

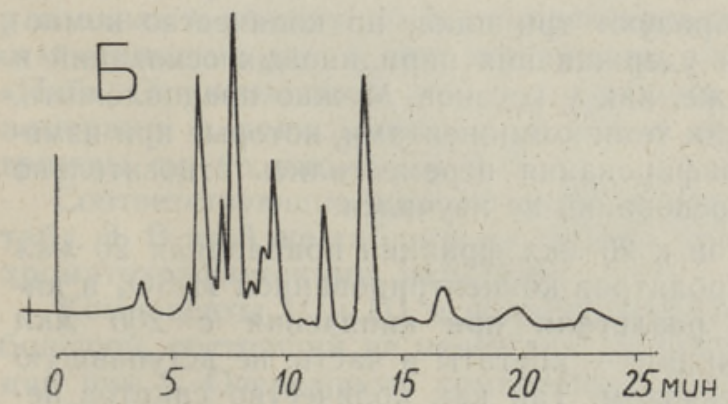

При анализе близкокипящих соединений в полигликолевой колонке хорошо разделяются соединения, принадлежащие к одной группе, но разные группы перекрываются. В неполярной апиезоновой колонке соединения хорошо разделяются на группы, однако внутри группы разделение нечеткое. Хроматограммы исходной фракции в двух полярных колонках изображены на рис. 1. Хроматограммы сходные, имеют пять основных пиков, толщина некоторых указывает на присутствие в них нескольких компонентов. Хромато-

Рис. 1. Хроматограммы фракции кетонов:

A -- в колонке № 3 (СЖФ - твин 80) при $180^{\circ} ; \mathrm{I}-\mathrm{V}$ - компоненты, конденсированные для дальнейшего исследования; $\overline{-}-$ в колонке Nㅗ 5 (СЖФ - полиэтиленгликоль). 
графирование при $200^{\circ}$ позволяет выделить после основных соединений еще три компонента, которые при анализе в других условиях были незаметны. Эти соединения, по-видимому, являются азотистыми основаниями, которые при низких температурах вследствие их высокой полярности адсорбируются на носителе неподвижной фазы. Это подтвердили опыты с пиридином и $\alpha$-пиколином, которые образовали нормальные пики только в колонке № 1 (полиэтиленгликоль/целлит). Хроматограмма исследуемой фракции, полученная в последней колонке (рис. 5 , A), непохожа на результаты, приведенные на рис. 1.

Несмотря на низкую температуру разделения $\left(100^{\circ}\right)$ и короткую колонку, количество пиков увеличилось. При дальнейшем понижении температуры хроматографирования (до $75^{\circ}$ ) часть пиков на хроматограмме переместилась, что указывает на присутствие в смеси компонентов из разных групп, времена удерживания которых при изменении температуры хроматографирования изменяются различно.

\section{Выделение спиртов и азотистых оснований из смеси кетонов}

Запах и физико-химические показатели фракции свидетельствовали - том, что она содержала азотистые основания. Проведенное параллельно с этой работой исследование других фракций показало присутствие алифатических спиртов [ $\left.{ }^{3}\right]$, наличие которых в этой фракции также достоверно. Углеводородов фракция не содержала, это было установлено при гидрировании микрореакторным газохроматографическим способом.

При определении групповой принадлежности компонентов, анализируемых газохроматографически, используют два способа: а) элюаты обрабатывают разными реактивами и по образующейся окраєке определяют группы [7], б) группы выделяют из исходного вещества до хроматографирования, соединения идентифицируют по дифференциальным хроматограммам [8]. Так как первый метод неприменим к аппарату с ионизационным детектором, пользовались последним. При выделении соединений использовали данные литературы [9]. Реакции проводили в пробирках с внутренним диаметром $3-5$ мм, слой разделяли с помощью капиллярных пипеток.

Для выделения оснований к 20 мкл фракции прибавляли 50 мкл $20 \%$-ной $\mathrm{H}_{2} \mathrm{SO}_{4}$, взбалтывали и нейтральные соединения экстрагировали 150 мкл бензола, прибавляя это количество в три приема. После нейтрализации кислотного слоя основания экстрагировали также бензолом. Растворитель испаряли в вакууме водоструйного насоса. Работали с колонкой № 1 (см. табл. 2). Хроматограммы экстракта и рафината приведены на рис. 2.

Пиридиновые основания образуют три пика, но количество компонентов в них больше. Времена удерживания пиридиновых оснований в применяемых условиях такие же, как у кетонов. Можно предположить, что азотистые соединенйя и были теми компонентами, которые при изменении температуры хроматографирования переместились относительно кетонов. Состав пиридиновых оснований не изучался.

Для ацетилирования спиртов к 20 мкл фракции прибавляли 20 мкл ацетангидрида, несколько микролитров концентрированной $\mathrm{H}_{2} \mathrm{SO}_{4}$ и кипятили. Избыток ангидрида разлагали при кипячении с 200 мкл $10 \%$-ной $\mathrm{NaOH}$. Продукты реакции - ацетаты и часть, не вступавшую в реакцию, экстрагировали бензолом. Так как количество спиртов не- 


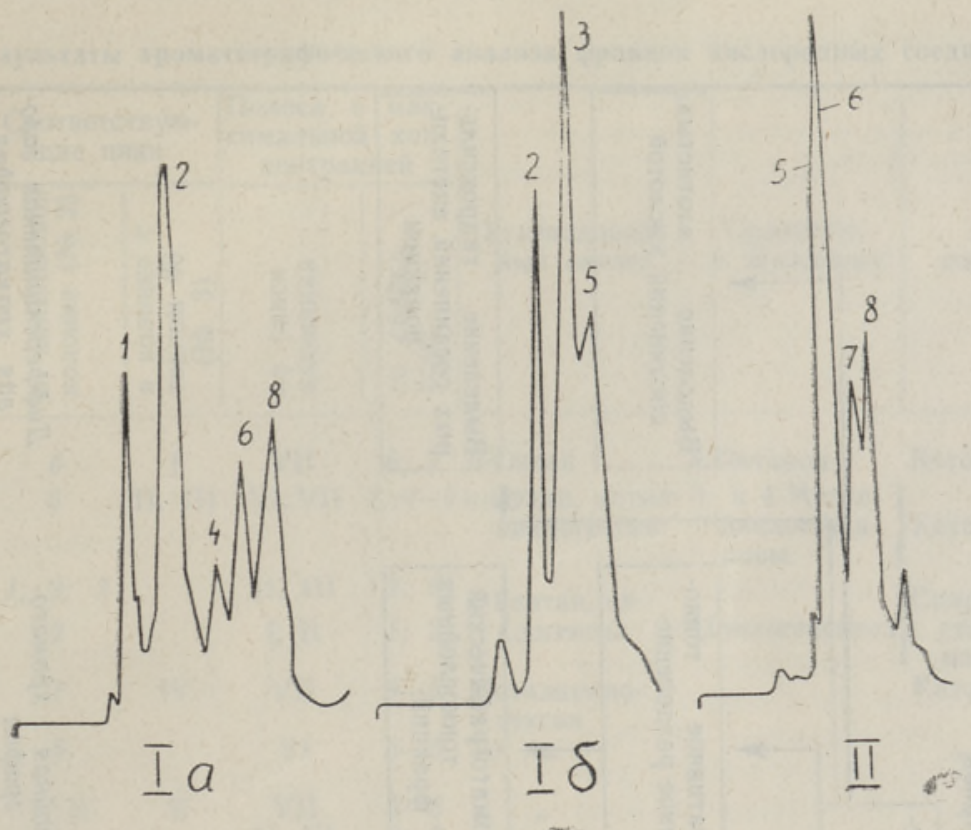

Рис. 2. Определение групповой принадлежности компонентов путем их селективного выделения:

I $\boldsymbol{a}$ - хроматограмма фракции после выделения азотистых оснований; I 6 - хроматограмма выделенных основаннй. Исходную фракцию см. на рис. 5. Хроматографирование проводилось в полигликолевой колонке (№ 1). II - хроматограмма фракции кислородных соединений после выделения спиртов. Исходную фракцию см. на рис. 6. Хроматограф:нрование проводнлось в алиезоновой колонке (№ 2). В результате ацетнлирования выделены компоненты $1-3$.

значительное и в полиэтиленгликолевой колонке они покрываются кетонами, для анализа использовали неполярную апиезоновую колонку. Результаты показаны на рис. 2. Из него видно, что в результате ацетилирования исчезла первая, маленькая группа соединений, содержашая не менее пяти компонентов. Спирты, как высокополярные вещества, выходят из неполярной апиезоновой колонки раныше других, это известно также из литературы $\left[{ }^{10}\right]$.

\section{Идентификация пиков эталонами}

В первую очередь оказалось необходимым установить соответствующие пики в различных колонках. Для проведения этого 15 мкл фракции разделили в колонке № 3 и конденсировали отдельно компоненты $\mathrm{I}-\mathrm{V}$, отмеченные на рис. 1. Эти компоненты анализировали на хроматографе «Пай». Основные пики исходной фракции на хроматограммах отмечены номерами: в полигликолевой $1-10$, в апиезоновой - $1-8$ (хроматограммы см. на рис. $5, A-8, A)$.

Соответствующие пики по данным анализа конденсатов показаны в табл. 3. В этой же таблице приведены результаты, полученные другими хроматографическими методами.

Компоненты II и III в полигликолевой колонке совпадают, образуя большой, состоящий не менее чем из четырех индивидуальных соединений пик 5. Очередность компонентов в полигликолевой колонке такая же. При анализе конденсатов не появились компоненты $3 ; 4 ; 5$ и 9 . Диф- 


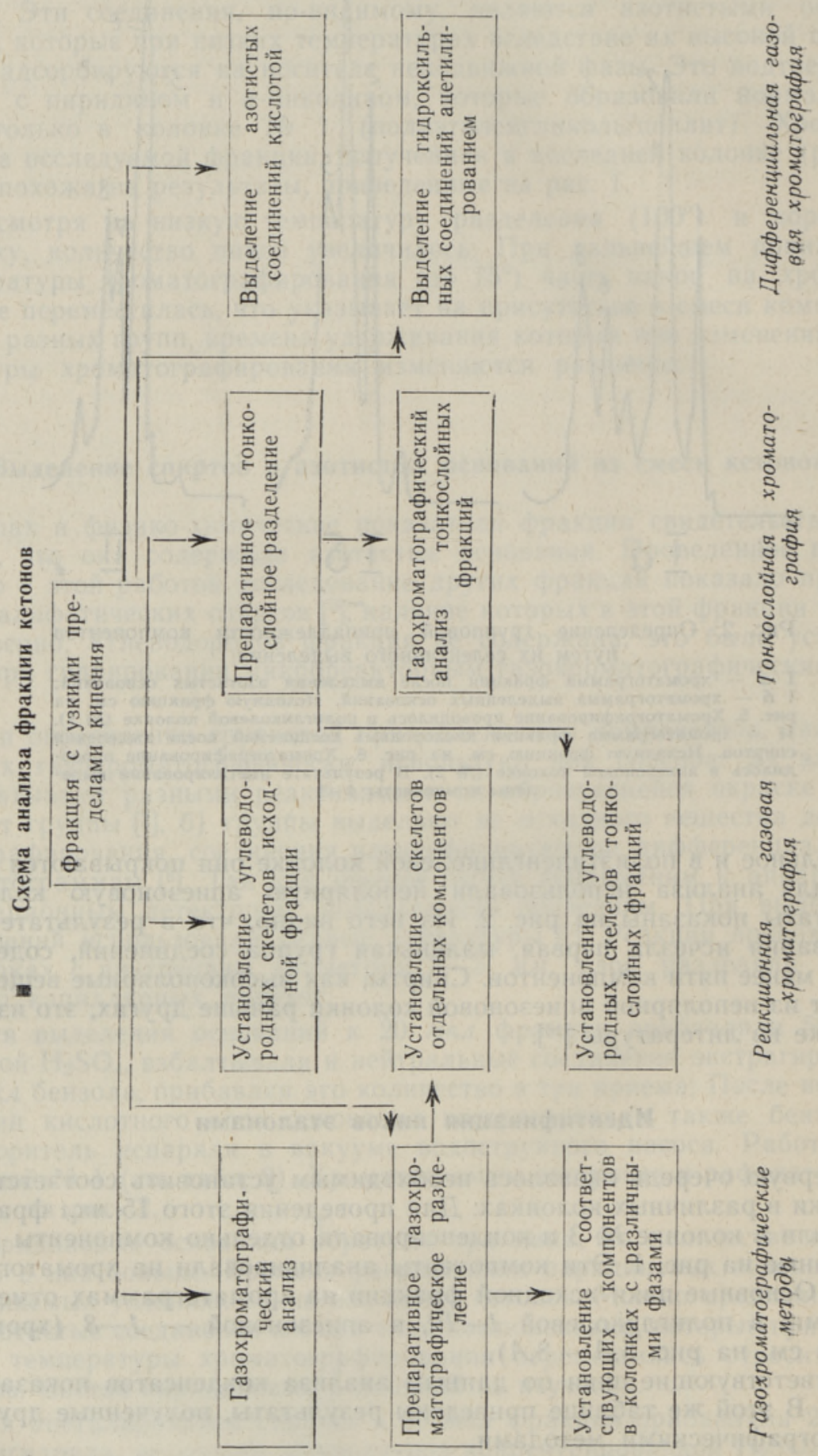


Таблица 3

Результаты хроматографического анализа фракции кислородиых соединений

\begin{tabular}{|c|c|c|c|c|c|c|c|}
\hline \multirow[b]{2}{*}{ 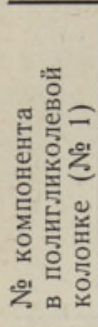 } & \multicolumn{2}{|c|}{$\begin{array}{c}\text { Соответствую- } \\
\text { щие пики }\end{array}$} & \multicolumn{2}{|c|}{$\begin{array}{l}\text { Полоса с мак- } \\
\text { симальной кон- } \\
\text { центрацией } \\
\end{array}$} & \multirow[b]{2}{*}{$\begin{array}{c}\text { Углеводород- } \\
\text { ный скелет }\end{array}$} & \multirow[b]{2}{*}{$\begin{array}{c}\text { Сравнение } \\
\text { с эталонами }\end{array}$} & \multirow[b]{2}{*}{$\begin{array}{c}\text { Группа } \\
\text { соединения }\end{array}$} \\
\hline & 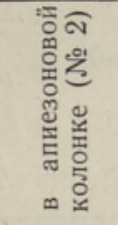 & 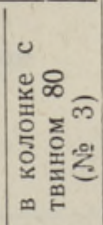 & 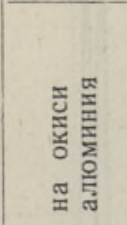 & 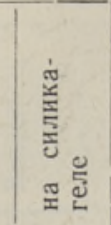 & & & \\
\hline 1 & 6 & I & VII & $6 ; 7$ & н-Октан & н-Октанон-2 & Кетон \\
\hline 2 & 5 & II, III & VI, VII & $2 ; 4-7$ & $\begin{array}{c}\text { н-Октан, метил } \\
\text { циклогексан }\end{array}$ & $\left.\begin{array}{c}\text { - 3- и 4-Метил- } \\
\text { циклогекса- } \\
\text { ноны }\end{array}\right\}$ & Кетоны \\
\hline $\left.\begin{array}{l}3 \\
4 \\
5\end{array}\right\}$ & $\begin{array}{c}1 ; 2 ; 3 \\
2\end{array}$ & & $\begin{array}{c}\text { II, III } \\
\text { I, II }\end{array}$ & $\begin{array}{l}2 ; 81 \\
1 ; 21\end{array}$ & $\begin{array}{c}\text { н-Гептан, ци- } \\
\text { клогексан }\end{array}$ & Циклогексанол & $\begin{array}{l}\text { Спирты, азоти- } \\
\text { стые соедине- } \\
\text { ния }\end{array}$ \\
\hline 6 & 7 & IV & VII & $3-5$ & $\begin{array}{l}\text { Метилцикло- } \\
\text { гексан }\end{array}$ & & Кетон \\
\hline 7 & 8 & & VI & $3-5$ & То же & & $"$ \\
\hline $\begin{array}{r}8 \\
9 \\
10\end{array}$ & $\begin{array}{c}7 ; 8 \\
4\end{array}$ & V & $\mathrm{V}, \underset{\mathrm{I}}{\mathrm{VII}}$ & $\begin{array}{c}3-5 \\
2 ; 3 \\
1\end{array}$ & 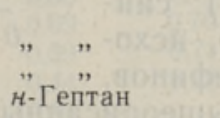 & н-Гептанол-1 & Спирт \\
\hline
\end{tabular}

ференциальный анализ групповой принадлежности компонентов показал, что пики 3 и 5 содержат пиридиновые основания, которые в колонке № 3 сильно адсорбировались и, следовательно, в конденсаты не попали.

В апиезоновой колонке конденсаты I и II почти совпадают, но очередность выхода их изменяется.

Идентификация пиков по эталонам - основной способ идентификашии компонентов при хроматографическом анализе, но в данном случае вследствие недостатка эталонов его применение ограничено. Каждый эталон хроматографировали в обеих колонках. Таким путем удалось идентифицировать только четыре компонента, которые также приведены в табл. 3.

\section{Исследование углеводородных скелетов компонентов}

При установлении углеводородных скелетов кислородных соединений использовали ранее разработанный метод (см. [1']). Использовали 2 мл катализатора $5 \% \mathrm{Pt} /$ силикагель, температуру катализа изменяли в пределах $280-340^{\circ}$.

Вначале гидрировали исходную фракцию при $330^{\circ}$, используя для анализа катализата колонку с ацетонилацетоном. Целью опыта было установить, образуются ли при катализе низкомолекулярные углеводороды $\mathrm{C}_{1}-\mathrm{C}_{5}$. Выяснилось, что не образуются. Это показывает, что в смеси отсутствуют простые и сложные эфиры, а также соединения с функциональными группами кислорода в конще цепи [12].

В дальнейшем проводили анализ катализата в колонке № 3 при $100^{\circ}$. Полученная хроматограмма показана на рис. 3. При идентификации пиков использовали эталоны и данные литературы [13], по которым относительные времена выхода бензола и $\mu$-октана равны соответственно 100 и 53,7 . Так как в продуктах катализа $\mu$-октан был одним из основных компонентов, при расчете относительных времен выхода его пик исполь- 
$R_{\text {; }}$ кетонов в тонком слое

(ПЭ - петролейный эфир, УЭ - уксусноэтиловый эфир)

\begin{tabular}{|c|c|c|c|c|c|c|}
\hline \multirow[b]{3}{*}{ Кетон } & \multicolumn{6}{|c|}{ Названия адсорбентсв и растворителей } \\
\hline & \multicolumn{3}{|c|}{ Силикагель } & Окись & \multicolumn{2}{|c|}{ алюминия } \\
\hline & 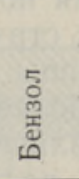 & 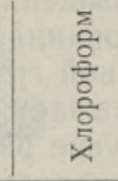 & 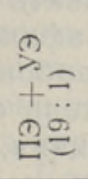 & (1) & $\begin{array}{l}+= \\
5= \\
0= \\
00 \\
\text { ம口 }\end{array}$ & 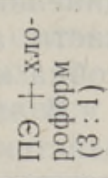 \\
\hline Бутанон-2 & 0,36 & 0,52 & & 0,42 & - & \\
\hline Пентанон-2 & 0,39 & 0,52 & 0,57 & 0,43 & 0,65 & 0,64 \\
\hline Пентанон-3 & 0,47 & 0,54 & 0,61 & 0,44 & 0,71 & 0,66 \\
\hline 3-Метилбутанон-2 & 0,44 & 0,62 & 0,59 & 0,43 & 0,71 & 0.66 \\
\hline Гексанон-2 & 0,48 & 0,58 & 0,54 & 0,45 & 0,66 & 0,72 \\
\hline Гептанон-3 & 0,53 & E 0,62 & 0,62 & 0,45 & 0,75 & 0,74 \\
\hline Гептанон-4 & 0,58 & 0,63 & 0,66 & 0,48 & 0,73 & 0,75 \\
\hline 2,4 -Диметилпентанон-3 & 0,52 & 0,62 & 0,68 & 0,50 & 0,72 & \\
\hline Октанон-2 & 0,49 & 0,59 & 0,55 & 0,46 & 0,71 & 0,74 \\
\hline Октанон-3 & 0,57 & 0,64 & 0,66 & 0,52 & 0,74 & 0,75 \\
\hline Нонанон-2 & 0,49 & 0,58 & 0,57 & 0,48 & 0,71 & 0,77 \\
\hline Нонанон-5 & 0,60 & 0,68 & 0,73 & 0,55 & 0,75 & 0,79 \\
\hline Деканон-3 & 0,64 & 0,69 & 0,70 & 0,55 & 0,78 & 0,79 \\
\hline Тридеканон-7 & 0,67 & 0,69 & 0,71 & 0,53 & 0,79 & 0,79 \\
\hline Циклопентанон & 0,32 & 0,44 & 0,38 & 0,37 & 0,55 & 0,57 \\
\hline Циклогексанон & 0,47 & 0,55 & & 0,42 & 0,66 & 0,63 \\
\hline 2-Метилциклогексанон & 0,57 & 0,66 & 0,70 & 0,55 & 0,75 & 0,75 \\
\hline 4-Метилциклогексанон & 0,44 & 0,52 & 0,40 & 0,43 & 0,66 & 0,67 \\
\hline Ацетофенон & 0,56 & 0,62 & 0,47 & 0,46 & 0,66 & 0,62 \\
\hline 4-Фенилбутанон-3 & 0,56 & 0,64 & 0,56 & 0,49 & 0,68 & 0,73 \\
\hline n-Фенилацетофенон & 0,46 & 0,46 & 0,41 & 0,53 & 0,56 & 0,59 \\
\hline Бензофенон & 0,59 & 0,63 & 0,52 & 0,38 & 0,60 & 0,58 \\
\hline Флуоренон & 0,56 & 0,62 & 0,60 & 0,38 & 0,55 & 0,58 \\
\hline
\end{tabular}

этого направления, превышает сто. Значительно меньше данных по непосредственному анализу этих соединений [14,15]. Это может быть обусловлено летучестью первых гомологов, а также тем обстоятельством, что кетоны часто уже отделены в виде производных. При хроматографировании адсорбентами служили окись алюминия и силикагель, элюентами - относительно малополярные растворители: петролейный эфир, бензол, диэтиловый эфир.

В настоящей работе кетоны после тонкослойного разделения подвергались газохроматографическому анализу, поэтому оказалось целесообразным их разделение в исходном виде. Предварительно были установлены закономерности их адсорбции на основе данных хроматографирования индивидуальных кетонов на тонком слое незакрепленной окиси алюминия и силикагеля. Использовали пластинки $20 \times 20$ см, толщина слоя составляла 0,5 мм. Для предотвращения улетучивания соединений хроматографирование вели между двумя пластинками. Таким образом удалось хроматографировать даже ацетон. Детектирование проводили парами йода. Результаты этих определений приведены в табл. 4. На их основе можно сделать следующие выводы:

1) при удлинении углеводородной цепи кетона $R_{f}$ увеличивается;

2) при передвижении карбонильной группы к середине цепи $R_{f}$ увеличивается;

3) циклические кетоны (гидроароматические) адсорбируются сильнее, чем алифатические с тем же количеством углеродных атомов; 
4) $R_{f}$ ароматических кетонов находится на том же уровне, что и алифатических, при этом с увеличением числа шиклов $R_{f}$ уменьшается.

Из сказанного следует, что степень адсорбции зависит от того, в какой мере углеводородная часть молекулы способна экранировать, препятствовать образованию связи между карбонильной группой и адсорбентом. Повышенную адсорбцию полициклических ароматических соединений может обусловливать повышенная полярность углеводородной части, а также плоская, зафиксированная структура ее, которая неспособна к экранированию карбонильной группы.

В этом случае силикагель оказывает более сильное адсорбирующее действие, чем окись алюминия, другие различия невелики. Хотя кетоны в тонком слое разделились, селективность разделения не очень высока; при тонкослойной хроматографии фенолов «ортоэффект» влияет значительно больше.

Как происходит в тонком слое отделение кетонов от других кислородных и азотистых соединений? Разделение исследовали на обоих адсорбентах, результаты приведены в табл. 5. Выясняется, что пириди-

Таблица 5

$R_{f}$ соединений, принадлежащих к разным группам

\begin{tabular}{|c|c|c|}
\hline \multirow{3}{*}{ Соединение } & \multicolumn{2}{|c|}{$\begin{array}{c}\text { Названия адсорбентов } \\
\text { и растворителей }\end{array}$} \\
\hline & Силикагель & Окись алюминия \\
\hline & Бензол & $\begin{array}{l}\text { ПЭ + этилаце- } \\
\text { тат }(9: 1)\end{array}$ \\
\hline
\end{tabular}

Октанон-2

Метилциклогексанон

н-Гексанол

Метилциклогексанол

Пиридин

2-Метилпиридин

$\begin{array}{ll}0,50 & 0,88 \\ 0,47 & 0,78 \\ 0,28 & 0,45 \\ 0,26 & 0,43 \\ 0,18 & 0,68 \\ 0,20 & 0,78\end{array}$

новые основания адсорбируются на силикагеле сильно, а спирты и кетоны - слабее. Все группы разделяются. На окиси алюминия очередность передвижения их изменяется; вследствие щелочных свойств адсорбента пиридиновые основания адсорбируются слабее, они передвигаются ближе к кетонам. Полученные данные показывают, что разделение соединений в тонком слое на группы возможно, при этом использование обоих адсорбентов может облегчить идентификацию компонентов.

\section{Тонкослойный анализ фракции кислородных соединений}

При препаративном тонкослойном разделении использовали пластинки $24 \times 24 \mathrm{~cm}$, толщина слоя адсорбента составляла 2 км. Растворителями служили: на окиси алюминия - смесь петролейного эфира и этилацетата $(19: 1)$, на силикагеле - бензол. Для детектирования пластинки короткое время выдерживали в парах йода и рассматривали в ультрафиолетовом свете. На пластинках было видно несколько желтых полос. Адсорбент разделили на 8-9 полос, вещество экстрагировали из них ацетоном. Для уменьшения потерь хроматографирование вели между двумя пластинками, при этом потери составляли 5-10\%. Распределение вещества на хроматограмме по полосам (концентрация на слое) 


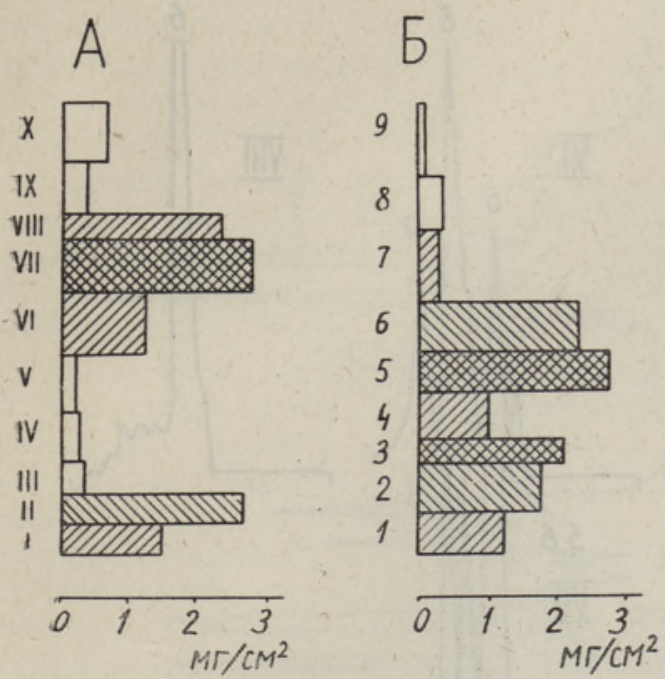

Рис. 4. Распределение кетонов по фракциям и их концентрация в тонком слое при препаративном тонкослойном разделении.

Адсорбенты: $A-$ окись алюминия и $5-$ силикагель.

показано на рис. 4. Видно, что материал разделился на две части. Судя по опыту, накопленному в ходе работы с индивидуальными соединениями, сильнее адсорбируемая часть на окиси алюминия должна состоять из спиртов, а на силикагеле - из пиридиновых оснований, что и подтверждается их характерным запахом.

Дололнительные данные дает газохроматографический анализ тонкослойных фракций. На рис. 5 и 6 показаны хроматограммы фракций тонкого слоя окиси алюминия в полигликолевых и апиезоновых колонках. На хроматограмме первой фракции выделяются два пика, соотвегствующие циклогексанолу и $н$-гептанолу- 1 . В апиезоновой колонке пиков больше, чем в полигликолевой.

Количество компонентов во второй фракции, тоже содержащей спирты, также невелико. Следующая фракция с высоким содержанием вещества (фр. VI) образует в полигликолевой колонке много пиков. Среди них

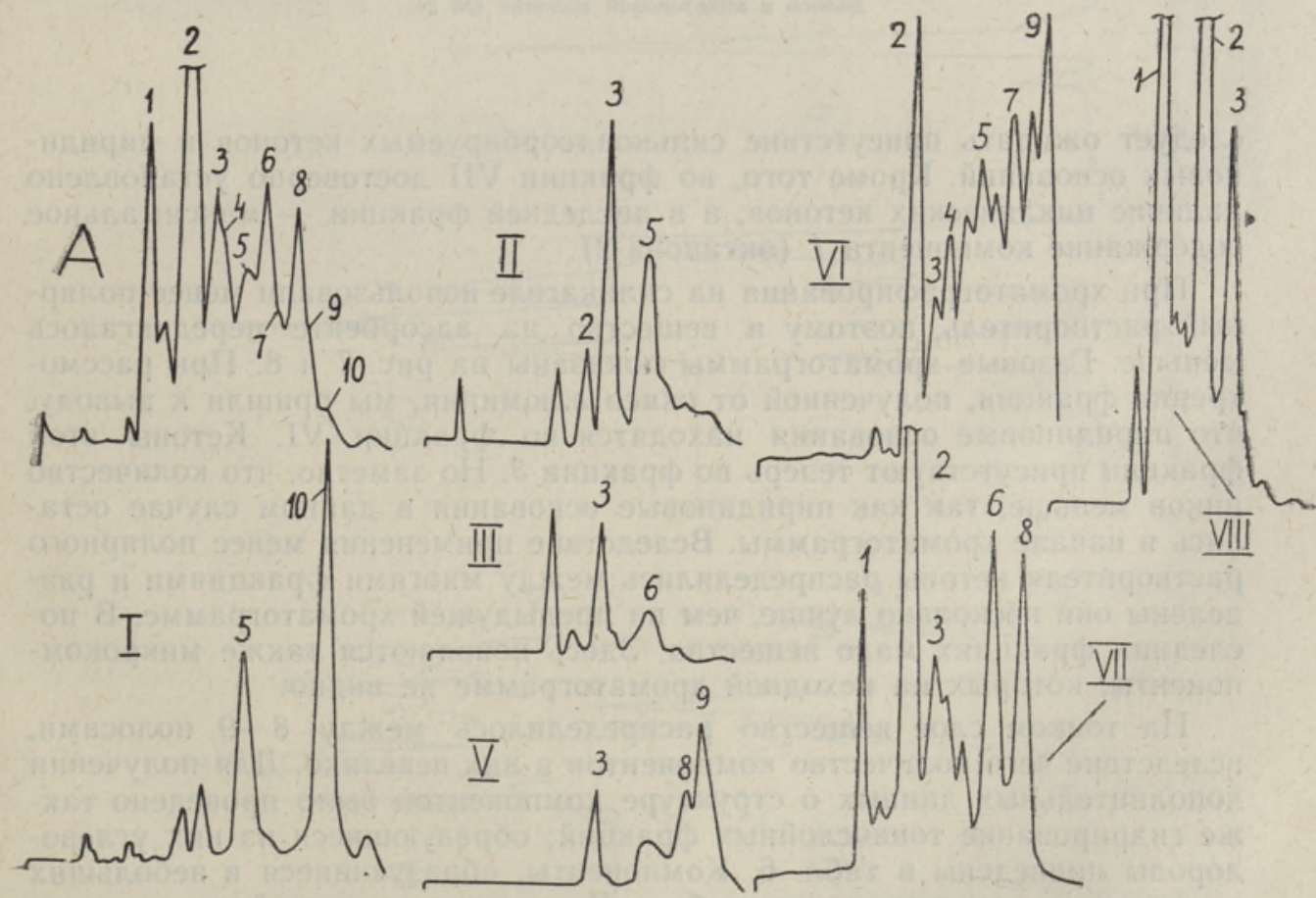

Рис. 5. Хроматограммы фракций, полученных при разделении концентрата кислородных соединений на тонком слое окиси алюминия.

A - исходное вещество; I-VIII - тонкослойные фракции. Хроматографирование проводнлось в полигликолевой колонке (№ 1). 


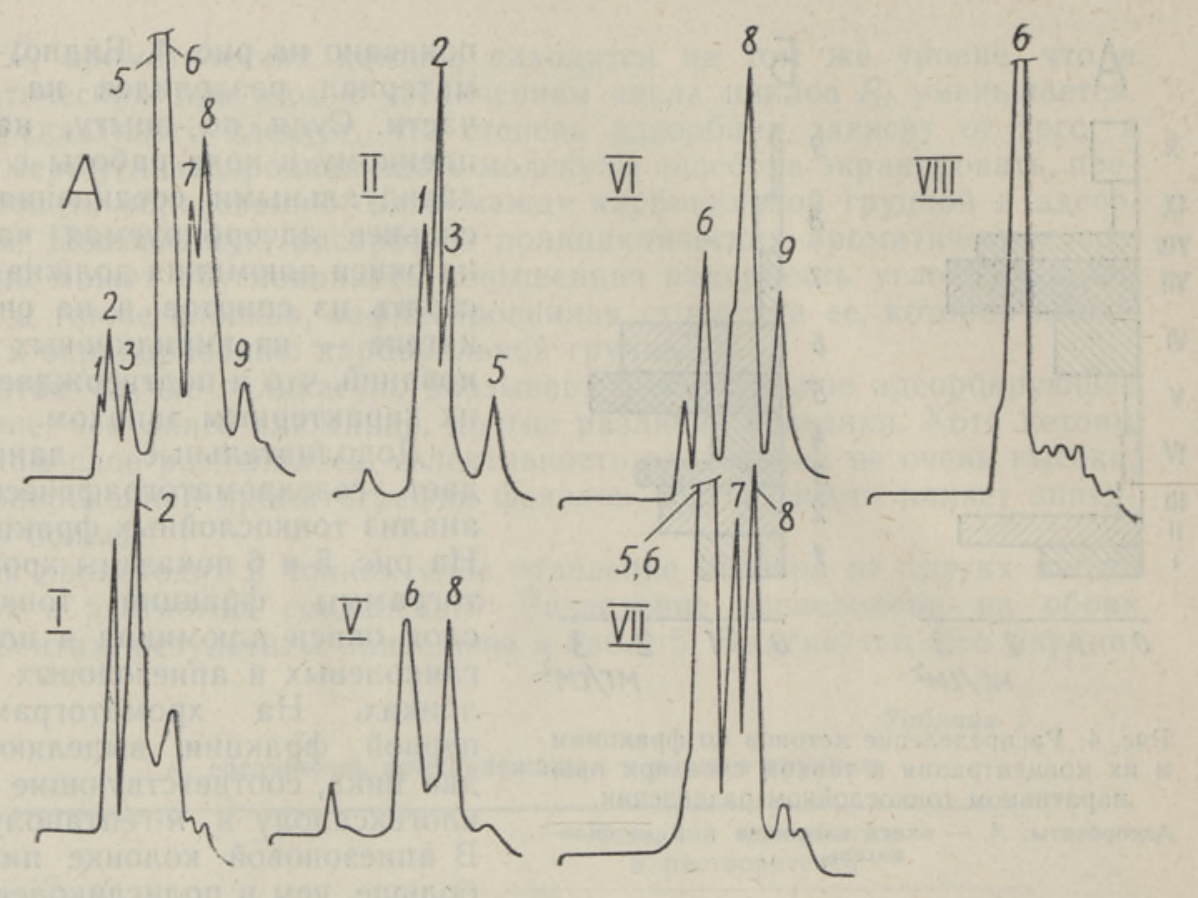

Рис. 6. Хроматограммы тонкослойных фракций, полученных при разделении на окиси алюминия.

A - нсходная смесь; I-VII - тонкослойные фракции. Хроматографиравашие проводнлось в апиезоновой колонке (N2 2).

следует ожидать присутствие сильноадсорбируемых кетонов и пиридиновых оснований. Кроме того, во фракции VII достоверно установлено наличие циклических кетонов, а в последней фракции - максимальное содержание компонента 1 (октанона-2).

При хроматографировании на силикагеле использовали менее полярғый растворитель, поэтому и вещество на адсорбенте передвигалось меньше. Газовые хроматограммы показаны на рис. 7 н 8 . При рассмотрении фракции, полученной от окиси алюминия, мы пришли к выводу, что пиридиновые основания находятся во фракции VI. Кетоны этой фракции присутствуют теперь во фракции 3. Но заметно, что количество пиков меньше, так как пиридиновые основания в данном случае остались в начале хроматограммы. Вследствие применения менее полярного растворителя кетоны распределялись между многими фракциями и разделены они несколько лучше, чем на предыдущей хроматограмме. В последних фракциях мало вещества. Здесь появляются также микрокомпоненты, которых на исходной хроматограмме не видно.

На тонком слое вещество распределилось между 8-9 полосами, вследствие чего количество компонентов в них невелико. Для получения дополнительных данных о структуре компонентов было проведено также гидрирование тонкослойных фракций; образующиеся из них углеводороды приведены в табл. 6. Компоненты, образующиеся в небольших количествах, заключены в скобки. Вследствие различий в условиях хроматографирования фракции с одним и тем же номером не содержат одних и тех же компонентов. 


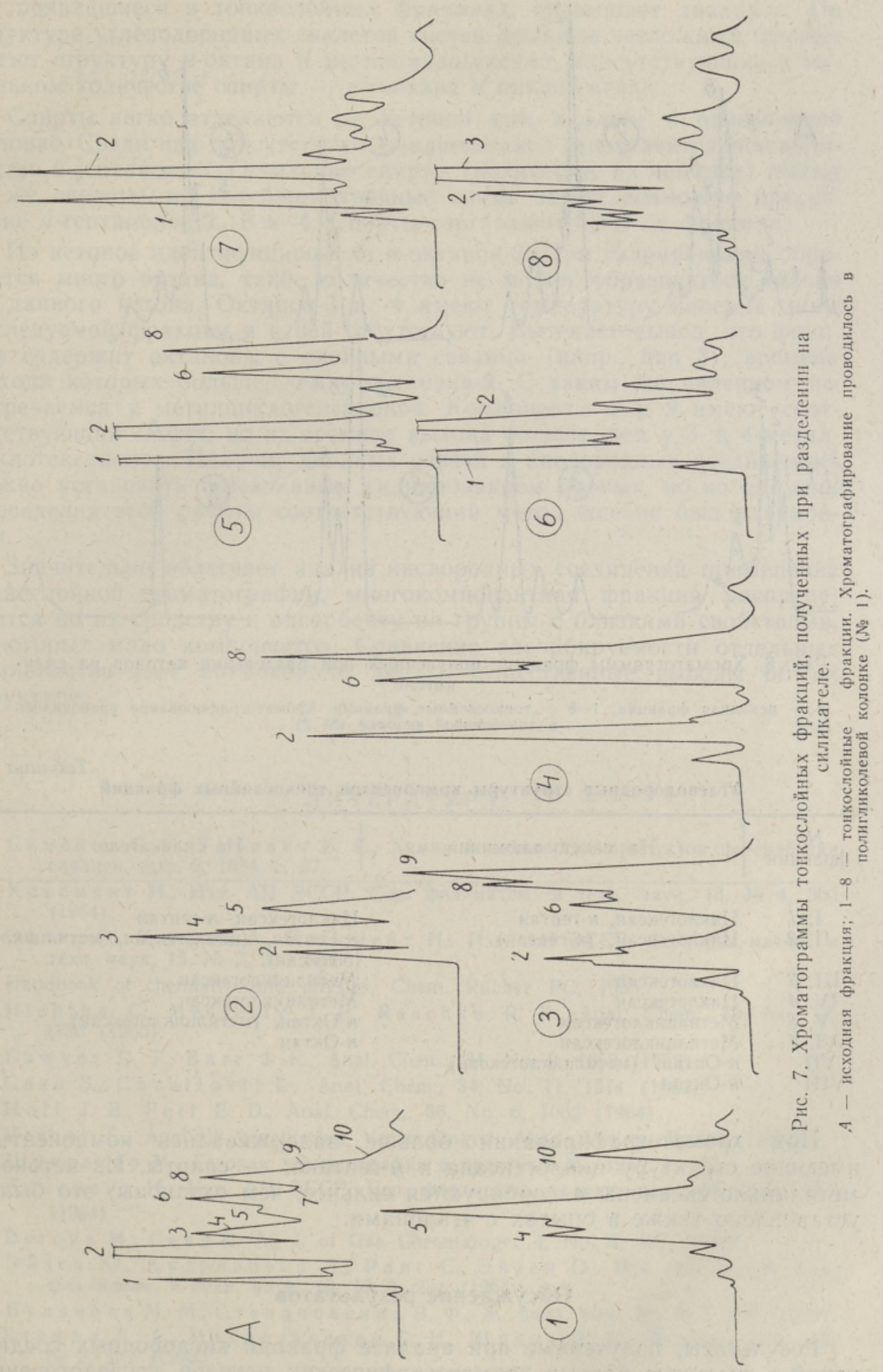



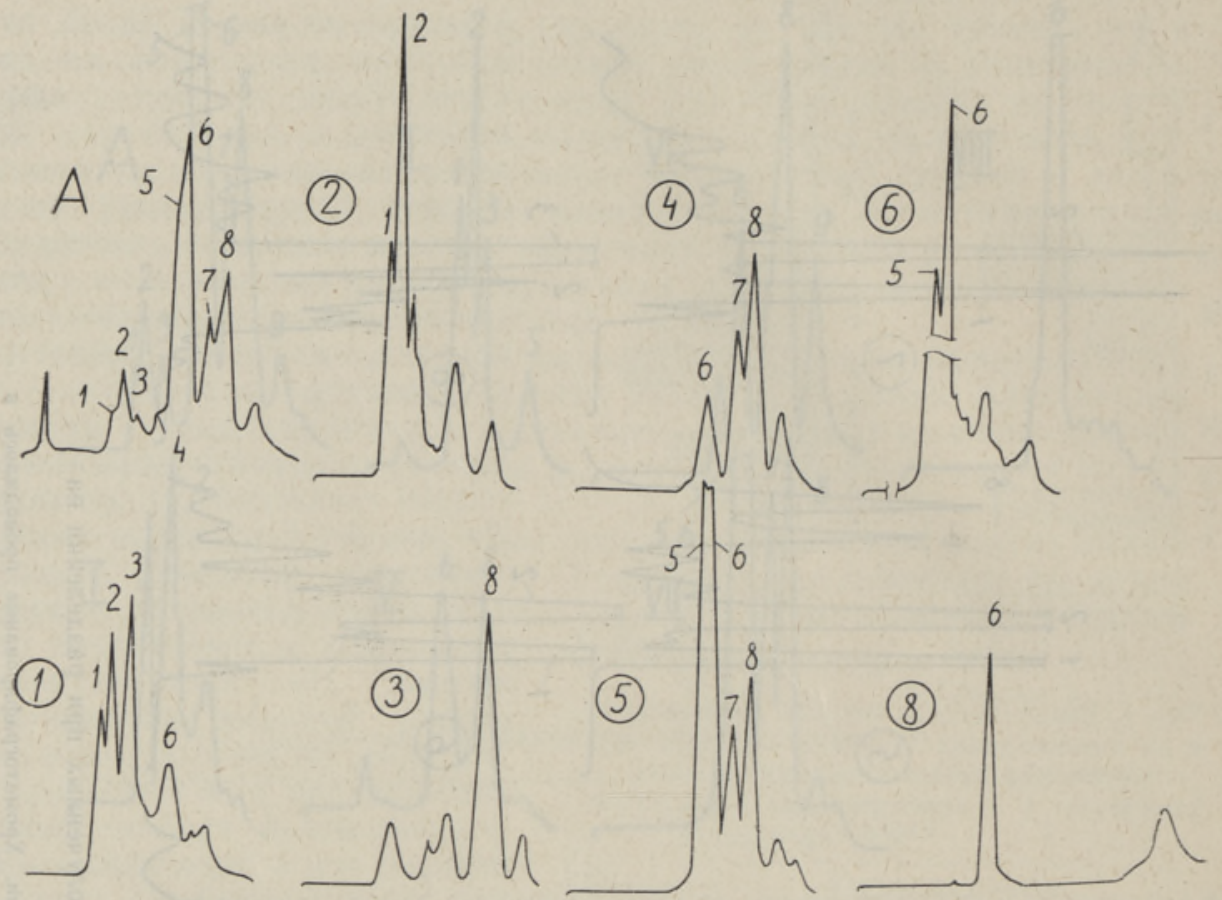

Рис. 8. Хроматограммы фракций, полученных при разделении кетонов на силикагеле.

$A$ - исходная фракция; $1-8-$ тонкослойные фракции. Хроматографирование проводилось в апиезоновой колонке (№ 2).

Углеводородные структуры компонентов тонкослойных фракций

Таблица 6

\begin{tabular}{l|l|l}
\hline $\begin{array}{c}\text { № } \\
\text { фркцци }\end{array}$ & На окиси алюминия & На силикагеле \\
\hline
\end{tabular}

I, 1 Циклогексан, $н$-гептан

II, 2 Циклогексан, (н-гептан)

III, 3 Циклогексан

IV, 4 Циклогексан

V, 5 Метилциклогексан

VI, 6 Метилциклогексан

VII $\quad \boldsymbol{H}$-Октан, (метилциклогексан)

VIII $\quad$-Октан

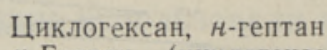

я-Гептан, (циклогексан, метилциклогексан)

Метилциклогексан

Метилциклогексан

н-Октан, (метилциклогексан)

н-Октан

При хроматографировании больше задерживались компоненты, имеющие структуру циклогексана и н-гептана, - спирты. Из кетонов метилциклогексаноны адсорбируются сильнее, чем октаноны; это было установлено также в опытах с эталонами.

\section{Обсуждение результатов}

Результаты, полученные при анализе фракции кислородных соединений с помощью разных хроматографических методов, сосредоточены в табл. 3. Там представлены данные о структуре десяти основных компонентов. Общее количество компонентов, если принимать в расчет так- 
же появившиеся в тонкослойных фракциях, превышает двадцать. По структуре углеводородных скелетов состав фракции несложный, кетоны имеют структуру $\boldsymbol{н}$-октана и метилциклогексана, присутствующие в маленьком количестве спирты - $\mathrm{H}$-гептана и циклогексана.

Спирты легко отделяются от кетонов при анализе в апиезоновой колонке. Среди них присутствуют циклогексанол и незначительное колинесто $\boldsymbol{H}$-гептанола-1. Остальные спирты (количество их немалое) имеют те же скелеты, но содержат двойные связи, также возможно присутствие $\boldsymbol{H}$-гептанолов-2, -3 и -4. Спирты составляют $5,5 \%$ от фракции.

Из кетонов идентифицировали $н$-октанон-2. При гидрировании образуется много октана, такое количество не может образоваться только из данного кетона. Октанон-3 и -4 имеют температуру кипения ниже нсследуемой фракции и в ней отсутствуют. Вытекает вывод, что фракция содержит октаноны с двойными связями (напр., пик 3), времена выхода которых больше, чем у октанона-2. С таким же явлением мы встречаемся у метилциклогексанонов. Компоненты 8 и 9 имеют соответствующий скелет, но их времена выхода больше, чем у 3- и 4-метилциклогексанонов. Наличие двойных связей в кислородных соединениях можно установить селективным гидрированием первых, но ко времени проведения этой работы соответствуюший метод еще не был разработан.

Значительно облегчает анализ кислородных соединений применение тонкослойной хроматографии, многокомпонентная фракция распределяется по их сродству к адсорбенту на группы с близкими свойствами, в которых мало компонентов. Сравнение адсорбируемости отдельных компонентов дает возможность делать существенные выводы об их структуре.

\section{ЛИТЕРА Т РА}

1. Семенов С. С., Гуревич Б. Е., Химия и технология продуктов переработки сланцев, вып. 2, 1954, с. 57.

2. Клесмент И., Изв. АН ЭССР. Сер. физ.матем. и техн. наук, 13, № 4, 305 (1964).

3. Эй зен О., Х аллик А., Клесмент И., Изв. АН ЭССР. Сер. физ.-матем. и техн. наук, 15, № 2, 230 (1966).

4. Handbook of chemistry and physics, Chem. Rubber PC, 1955.

5. Hishtha C., Messerly J. P., Reschke R. F., Anal. Chem., 32, No. 13, 1730 (1960).

6. S a w ye r D. T., B a r r J. K., Anal. Chem., 34, No. 9, 1052 (1962)

7. C a su B., C avall o tt i L., Anal. Chem., 34, No. 11, 1514 (1962).

8. Hoff J. E., Feit E. D., Anal. Chem., 36, No. 6, 1002 (1964).

9. Veibel S., Analytik organischer Verbindungen, Akad. Verlag, Berlin, 1960.

10. Ш и нгли а р М., Газовая хроматография в практике. М., 1964, с. 143.

1i. Қлесмент И., Изв. АН ЭССР, Сер. физ.-матем. и техн. наук, 13, № 4, 297 (1964).

12. B eroza M., Coad R. A., J. of Gas Chromatogr., 4, No. 6, 199 (1966).

13. Эйзен Ю., Кудрявцева Л., Р анг С., Эйзен О.. Изв. АН ЭССР. Сер. физ,-матем. и техн. наук, 13, № 3, 234 (1964).

14. Бул ан о в М. М., С теп анов ск а В. Ф., Ж. анал. хим., 20, № 7, 859 (1965).

15. Хей фиц Л. А., Молдованская Г. И., Щулов Л. М., Ж. анал. хим., 18, № 2, 267 (1963).

Ннститут химии

Академии наук Эстонской ССР
Поступила в редакцию 31/I 1967 


\section{KLESMENT}

\section{KETOONIDE ANALUUS KROMATOGRAAFILISTE MEETODITEGA}

Põlevkiviōlist eraldatud ketoonide ühe fraktsiooni koosseisu uuriti gaasikromatograafiaga, õhukesekihilise kromatograafiaga ja mikroreaktor-gaasikromatograafilisel seadmel vastavateks süsivesinikeks hüdrogenolüüsimise teel. Neid meetodeid kasutati kombineeritult. Fraktsioonis leiduvad ketoonid olid n-oktaani ja metüültsükloheksaani struktuuriga, väikesel hulgal esinevad alkoholid - n-heptaani ja tsükloheksaani struktuuriga. Oletatakse, et suur hulk ühendeid sisaldab küllastamata sidemeid.

\section{KLESMENT}

\section{ANALYSE DER KETONE DURCH CHROMATOGRAPHISCHE METHODEN}

Es wurde die Zusammensetzung einer Fraktion aus Brennschieferteer getrennter Ketone untersucht. Man benutzte Kombinationen verschiedener Methoden: Gaschromatographie, Dünnschicht-Chromatographie, Hydrogenolyse zu den betreffenden Kohlenwasserstoffen auf einer Mikroreaktor-gaschromatographischen Anlage. Die Fraktion enthält Ketone von der Struktur des $n$-Oktans und des Methylzyklohexans sowie eine kleine Menge Alkohole von der Struktur des $n$-Heptans und des Zyklohexans. Man vermutet, daß eine große Menge Verbindungen ungesättigte Bindungen enthält. 